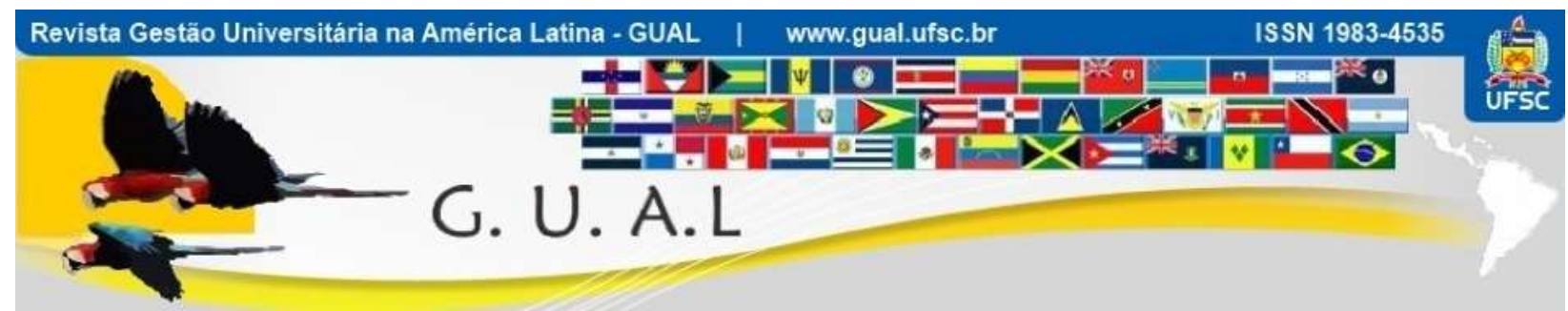

DOI: https://doi.org/10.5007/1983-4535.2021.e76165

\title{
FATORES CONSTITUTIVOS DA ESCOLHA PELA GRADUAÇÃO DE CIÊNCIAS CONTÁBEIS
}

\section{FACTORS THAT CONSTITUTE CHOICE BY GRADUATION OF ACCOUNTING SCIENCES}

\author{
Silvio Paula Ribeiro, Doutor \\ https://orcid.org/0000-0001-9169-1190 \\ spribeiro@hotmail.com \\ Universidade Federal de Mato Grosso do Sul | Campus II de Três Lagoas \\ Três Lagoas | Mato Grosso do Sul | Brasil \\ Sirlei Tonello Tisott, Doutora \\ https://orcid.org/0000-0001-9432-234X \\ sirlei.tonello@yahoo.com.br \\ Universidade Federal de Mato Grosso do Sul | Campus II de Três Lagoas \\ Três Lagoas | Mato Grosso do Sul | Brasil \\ Clari Schuh, Doutora \\ https://orcid.org/0000-0002-0972-0579 \\ clarischuh@uol.com.br \\ Universidade de Santa Cruz do Sul | Curso de Ciências Contábeis \\ Santa Cruz do Sul | Rio Grande do Sul | Brasil \\ Tamires Sousa Araújo, Doutora \\ https://orcid.org/0000-0002-0926-151X \\ tamires.sousa@ufms.br \\ Universidade Federal de Mato Grosso do Sul | Campus II de Três Lagoas \\ Três Lagoas | Mato Grosso do Sul | Brasil \\ André Luiz Francisco, Mestre \\ https://orcid.org/0000-0002-6727-6701 \\ andre.francisco@ufms.br \\ Universidade Federal de Mato Grosso do Sul | Campus II de Três Lagoas \\ Três Lagoas | Mato Grosso do Sul | Brasil
}

Recebido em 01/agosto/2020

Aprovado em 24/fevereiro/2021

Publicado em 01/maio/2021

Sistema de Avaliação: Double Blind Review

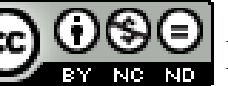

Esta obra está sob uma Licença Creative Commons Atribuição-Uso. 


\begin{abstract}
RESUMO
O presente estudo tem o objetivo de identificar os fatores que constituem a escolha pela graduação em Ciências Contábeis, sob a ótica de discentes de uma Instituição de Ensino Superior Federal localizada no Estado do Mato Grosso do Sul. O estudo caracteriza-se como descritivo, com abordagem quantitativa do problema. A obtenção dos dados erigiu-se da aplicação de questionário estruturado, junto aos graduandos de Ciências Contábeis. A análise dos dados obtidos foi baseada em análise fatorial exploratória. A partir dos resultados, foi possível identificar 10 (dez) fatores direcionadores da escolha pela graduação em contabilidade: a vocação pessoal, o curso não foi a primeira opção do aluno, os pais não gostaram da escolha, os discentes consideram não ter condições financeiras, avaliam que o curso proporciona autonomia, oferece oportunidades de criar a própria empresa, desenvolve o intelectual, contribui com o crescimento profissional e traz estabilidade aos graduados em contabilidade. Estes fatores foram classificados em cinco componentes, com percentual de 78,548 de variância explicada.
\end{abstract}

Palavras-chave: Ciências Contábeis. Profissão. Discentes. Análise fatorial.

\begin{abstract}
The study had the interest of identifying the factors that constitute the choice for the graduation in Accounting Sciences, from the perspective of students of a Federal Higher Education Institution located in the State of Mato Grosso do Sul, The research is characterized as descriptive, with a quantitative approach to the problem. The collection of data arose from the application of a questionnaire with undergraduates in Accounting Sciences. The analysis of the data obtained, was based on exploratory factor analysis. Based on the results, it was possible to identify 10 (ten) factors that contribute to the choice of undergraduate accounting, they are: personal vocation, the course was not the student's first choice, the parents did not like the choice, the students consider it not have financial conditions, assess that the course provides autonomy, offers opportunities to create their own company, develops intellectuals, contributes to professional growth and brings stability to accounting graduates. Which were classified into five components, with a 78.548 percentage of explained variance. However, the students only got to know the course during the entrance exam and the variables related to the job and socioeconomic market do not present themselves as motivators in choosing the profession.
\end{abstract}

Keywords: Accounting Sciences. Profession. Students. Factor analysis. 


\section{INTRODUÇÃO}

Entender a dinâmica que perpassa a escolha profissional e o comprometimento inerente a este processo, tanto do ponto de vista individual quanto coletivo, "é de grande relevância para o desenvolvimento e consolidação da profisssão" (SANTOS; ALMEIDA, 2018, p. 115), enfatizando-se que o curso de Ciências Contábeis tem crescido gradativamente ao longo dos últimos anos, alcançando a classificação de quarto lugar entre os cursos de graduação com maior número de matrículas. Conforme o INEP (2018), foram 362.042 acadêmicos matriculados no ano de 2017. Esta procura pelo curso evidencia o alto interesse pelas possibilidades de emprego na área.

As Ciências Contábeis oferecem diversas opções de emprego ao bacharel como: contador, controller, perito, auditor, analista. Infelizmente, “é ilusão pensar que todos os ingressantes e/ou egressos dos cursos queiram construir uma carreira profissional nessa área" (Santos \& Almeida, 2018, p. 115). Entretanto, Peleias, Nunes e Carvalho (2017, p. 41) salientam que a escolha profissional na área contábil ou não, depende de decisão a longo prazo "e pode parecer definitiva, induzindo o jovem a pensar que não poderá ou não haverá chance para mudar sua decisão no futuro".

Os motivos de escolha da profissão contábil podem ser o resultado dos fatores intrínsecos e extrínsecos da profissão (HSIAO; NOVA, 2016; NG; CHONG; H’NG, KHOR, 2017; PRATAMA, 2017; THING; JALALUDIN, 2018). Diante destes fatores, a escolha pela graduação em Ciências Contábeis, vem sendo abordada por diversos estudos (ALANEZI; ALFRAIH; HADDAD; ALTAHER, 2016; CAVALCANTE， 2009; CHEN; JONES; MCINTYRE， 2008; DALCI; ARASLI; TÜMER; BARADARANI， 2013; DURGUT; PEHLIVAN; 2019; GERMANOU; HASSALL; TOURNAS, 2009; GRABOWSKI, 2019; INDRIANI; MURTI, 2018; KHALID et al. 2018; LOPENS; MEURER, 2019); MARQUES; SALVIANO; SILVA, 2016; NG et al. 2017; PELEIAS; NUNES; CARVALHO, 2017; POLITELO; MANFROI; CUNHA, 2013; PRATAMA, 2017; SOUZA; DURSO, 2018; SRIREJEKI; SUPENO; FATURAHMAN，2019; THING; JALALUDIN，2018; UYAR; GÜNGÖRMÜŞ; KUZEY, 2011; WALLY-DIMA, 2013). Esses autores, além de abordarem o tema, ainda relatam que os fatores motivadores do crescimento da graduação estão associados a clareza de autoconceito, as expectativas de autoconhecimento, a empregabilidade, a influência pais/pares, os fatores socioeconômicos e planejamento da carreira. Conforme 
Peleias, Nunes e Carvalho (2017), os respectivos fatores podem ser classificados em externos ou internos, isto é, intrínsecos e extrínsecos ao indivíduo.

As pesquisas mencionadas acima podem dar suporte às discussões sobre o perfil do mercado de trabalho da área contábil para os futuros profissionais (SANTOS; ALMEIDA, 2018). Neste contexto, a presente pesquisa teve como objetivo geral: identificar os fatores que constituem para a escolha da graduação em Ciências Contábeis, sob a ótica de discentes de uma Instituição Federal de Ensino Superior, localizada no Estado do Mato Grosso do Sul. De forma específica, observar quais fatores podem funcionar como mecanismos contribuidores da construção dos projetos políticos pedagógicos do curso, bem como nortear as pesquisas que aumentem a qualidade da formação dos acadêmicos em contabilidade.

O estudo justifica-se em decorrência do crescimento de ingressantes no curso de Ciências Contábeis nas universidades brasileiras. Além de contribuir na elaboração dos projetos pedagógicos e com pesquisas relacionadas à carreira e à profissão contábil (INEP, 2018, PELEIAS; NUNES; CARVALHO, 2017). Os resultados da pesquisa poderão assessorar também as universidades para a formulação de políticas mais favoráveis ao desenvolvimento do interesse dos alunos na escolha da carreira no âmbito da contabilidade.

Ao pensar na escolha da profissão que o candidato a graduação pretende realizar, Srirejeki, Supeno e Faturahman (2019, p. 11), afirmam que "as agências reguladoras podem usar essas descobertas como base para desenvolver políticas que orientem universidades ou órgãos profissionais para tornar a profissão contábil mais desejável”. Junto a esta asserção, Cepa (2015) e Marques, Salviano e Silva (2016) relatam que as pesquisas nessa temática podem ser relevantes na orientação de ações a serem desenvolvidas pelos diferentes intervenientes da formação de profissionais, com o objetivo de angariar níveis de excelência na área contábil, reforçando o status da profissão.

Neste sentido, a prévia dos resultados da análise fatorial permitiu identificar e classificar 10 (dez) fatores que constituem a escolha pela graduação em Ciências Contábeis, mediante a perspectiva do acadêmico deste curso, são eles: vocação, não foi a primeira opção, meus pais não gostaram, não ter condições financeira, autonomia, desenvolvimento intelectual, conheci durante o vestibular, crescimento profissional e estabilidade. Tais fatores que contribuem com a escolha da profissão foram classificados 5 (cinco) componentes, com $78,548 \%$ de variância explicada. Apontamentos explicitados em detalhes, no item referente à análise dos dados. 


\section{REFERENCIAL TEÓRICO}

\subsection{ESCOLHA DA PROFISSÃO CONTÁBIL}

Os principais aspectos motivadores da escolha pela carreira em contabilidade estão relacionados ao mercado de trabalho e a possibilidade de trabalhar em uma grande empresa (DURGUT; PEHLIVAN, 2019). Lopens e Meurer (2019, p. 46), em estudo realizado junto a 309 discentes de Ciências Contábeis das Instituições de Ensino Superior (IES) Públicas do Brasil, constataram que "o histórico social e as experiências passadas do sujeito conduzem para a priorização de elementos no que tange a prospecção de carreira pública ou privada".

Srirejeki, Supeno e Faturahman (2019) relatam que 439 estudantes de contabilidade de universidades da Indonésia expressam que o fator intrínseco (atitude) e a influência dos pais ou pares (norma subjetiva) afetam a intenção dos alunos de seguir carreira na área contábil. Grabowski (2019) discute duas situações: a percepção do aluno sobre a importância das competências e habilidades necessárias na profissão contábil. Sob estas duas condições o autor assevera que a comparação da literatura é difícil visto que a importância das habilidades é testada em uma ampla variedade de métodos, enquanto que, o escopo e o tipo de habilidades variam em grau substancial. Além dessas limitações, os alunos percebem que as habilidades técnicas de contabilidade não são suficientes para trabalhar na profissão, necessitando de outras habilidades no campo da comunicação, trabalho em equipe, tomada de decisão, pensamento analítico e lógico, competências interpessoais e comportamento e ética profissional.

Sob esta esteira de sentidos, Santos e Almeida (2018) organizaram uma investigação quanto ao desejo de se seguir a área contábil, profissionalmente, a partir dos relatos de 691 alunos concluintes dos cursos de Ciências Contábeis das universidades públicas do estado do Paraná. Os relatos revelaram ser preponderantes as variáveis: atitudes, norma subjetiva e controle comportamental percebido. Estas afetam a intenção dos alunos e os predispõem a uma carreira na área contábil.

Outra pesquisa realizada na Malásia, com 193 graduandos em contabilidade nas universidades públicas e privadas, publicada por Thing e Jalaludin $(2018$, p.66) considerou como principais resultados: "a motivação intrínseca, motivação extrínseca, influência de terceiros, exposição na carreira, custo de oportunidade e intenção de trabalhar no exterior". $\mathrm{Ng}$ et al. (2017) demonstraram também, em pesquisa junto aos alunos de uma universidade privada, na mesma territorialidade, que os fatores determinantes na escolha da profissão 
contábil estão vinculados a motivações intrínseca e podem ser significativos mediante os cuidados relacionados à opção pela carreira.

Sobre a intenção dos alunos do ensino médio em cursar contabilidade no nível superior, Khalid et al. (2018) expõem que as oportunidades de carreira e a percepção sobre a profissão contábil não foram geradoras de nenhuma influência quanto a escolha profissional. Em contrapartida, Souza e Durso (2018), movidos pelo propósito de identificar os fatores que interferem no tipo de motivação de estudantes-trabalhadores e trabalhadores-estudantes para realização da graduação em Ciências Contábeis, relataram em seu trabalho conjunto que o nicho de mercado contábil e a possibilidade de aprofundar os conhecimentos na área levaram os alunos a optarem pelo curso.

Os fatores determinantes a escolha profissional na área de Ciências Contábeis identificados na Indonésia foram a opção de carreira no setor público, a perspectiva salarial, seguida de reconhecimento profissional, incentivo/influência da família e colegas (INDRIANI; MURTI, 2018). Em pesquisa, também na Indonésia, Pratama (2017) afirmaram que a decisão de carreira pode ser influenciada por diversos fatores, como os derivados da teoria do comportamento planejado: fatores extrínsecos, fatores intrínsecos e normas sociais.

Diante dos fatores determinantes na escolha do curso de Ciências Contábeis por discentes de instituições de ensino superior particulares na cidade de São Paulo, Peleias, Nunes e Carvalho (2017) constataram que os fatores podem ser internos e externos, com influencias de aspectos como: empregabilidade, perspectiva de carreira e o fato de os pais não exercerem influência direta na escolha do curso dos estudantes pesquisados.

Hsiao e Nova (2016) demonstraram, mediante resultados de suas pesquisas, que as pessoas que escolhem a contabilidade como carreira foram influenciadas pela criatividade, independência, ambiente desafiador/dinâmico, aumento de renda, disponibilidade de emprego, amigos, professores e outras pessoas importantes. Os sujeitos eleitos pelos autores não sofreram influência dos fatores sociais, como: trabalhar com pessoas, contribuir para a sociedade e a família. Os respondentes explicitaram que os motivadores de suas escolhas se vincularam a mais autonomia, criatividade e flexibilidade no trabalho, e ainda a preocupação com a segurança no emprego e com o dinheiro.

Conforme Marques, Salviano e Silva (2016), a possibilidade de atuar em diversas áreas, imagem e reputação da instituição, a visão de que o curso evolui no mercado, de que a profissão proporciona autonomia de atuação, além de ampliar a cultura, o desenvolvimento geral e é vinculada a grande oferta de emprego, foram aspectos salientados como 
preponderantes, segundo a visão dos alunos, para a escolha da graduação em Ciências Contábeis. Os fatores com menor relevância, para estes respondentes, foram: obtenção de custeio pela empresa onde trabalha/trabalhou, influência da empresa onde trabalha/trabalhou, administrar empresa da família e tradição familiar.

Em pesquisa realizada no Kuwait, Alanezi et al. (2016) revelaram que as oportunidades de carreira, o prestígio e o assunto como alvo de interesse possuem uma influência considerável na decisão dos acadêmicos ao optarem pela profissionalização na área contábil. Além disso, não há impacto quanto a diferença de gênero ou tipo de ensino médio cursado, na decisão dos estudantes que cursam Ciências Contábeis.

Em relação ao que concerne à pesquisa realizada em Portugal, Cepa (2015, p. 6) explicita que, de acordo com as percepções dos alunos, o ingresso na área contábil ocorre porque a contabilidade e a profissão contábil são "interessantes", destacando que "os fatores de influência mais significativos são o interesse e o gosto próprio pela área, a experiência e formação anterior nessa mesma área", enquanto que, para uma parcela de alunos o acesso à área contábil não foi primeira opção de escolha.

Na Nigéria, por sua vez, as respostas obtidas junto a estudantes, mediante a pesquisa de Umar (2014, p. 9) mostra que "os pais, interesses pessoais e outros fatores (parentes) influenciam direta ou indiretamente a decisão de empreender na carreira de contabilidade. Por outro lado, os alunos são motivados pelas perspectivas de futuro, prestígio e melhor salário associado à profissão contábil”.

Em relação a formação em contabilidade Politelo, Manfroi e Cunha (2013) afirmaram que a formação em nível superior tem uma influência positiva sobre o ingresso dos estudantes no mercado de trabalho e que o curso de Ciências Contábeis se erige como via atrativa aos sujeitos ingressantes do ensino superior, em decorrência da oferta proporcionada pelo mercado de trabalho e melhores condições de vida vinculada a profissionalização em uma determinada área. Nesta perspectiva, Dalci et al. (2013) articula que os resultados de pesquisa realizada no Irã mostraram que os estudantes de Ciências Contábeis atribuem profunda importância aos fatores financeiros e de mercado de trabalho como fatores primordiais para escolha profissional que fizeram.

Considerações obtidas pela coleta de dados junto aos estudantes de contabilidade do último ano da Universidade do Botsuana, em fase de conclusão do curso em contabilidade, mostram que os principais fatores que influenciam a escolha pela contabilidade "incluem disponibilidade de oportunidades de aprimoramento, interesse pessoal no assunto, 
disponibilidade de emprego após a graduação, paixão pela profissão e altos ganhos em comparação com outras profissões" (WALLY-DIMA, 2013, p.464). O estudo também revelou que cerca de um terço desses alunos tomaram a decisão pela profissão contábil durante o ensino médio.

Estudantes da Malásia que visitavam uma universidade na Inglaterra responderam a um questionário de pesquisa, cujo resultado revelou em dois grupos distintos, formados por estudantes malaios e ingleses, as perspectivas positivas, na profissão contábil e, também, apontou que há uma correlação significativa na intenção de seguir carreira na profisssão contábil para ambos os grupos (GERMANOU; HASSALL; TOURNAS, 2009).

De acordo com Peleias, Nunes e Carvalho (2017), os fatores que contribuem com a escolha da graduação podem ser classificados em externos e internos, isto é, extrínsecos ou intrínsecos. Assim, os autores os dividiram em internos e externos, na sequência reuniram em 06 (seis) temas e, por fim, levantaram 20 (vinte) variáveis entre os seis fatores eleitos responsáveis por motivar a escolha da graduação em Ciências Contábeis. A Tabela 1 demonstra o panorama da pesquisa realizada.

Tabela 1 Fatores da escolha pela profissão contábil

\begin{tabular}{|c|c|}
\hline Temas & Variáveis \\
\hline \multicolumn{2}{|l|}{ Fatores Internos } \\
\hline \multirow{2}{*}{$\begin{array}{c}\text { Clareza de auto } \\
\text { conhecimento }\end{array}$} & 1. Escolhi cursar Ciências Contábeis por ser minha vocação. \\
\hline & 6. A profissão de contador me trará status. \\
\hline \multirow{5}{*}{$\begin{array}{l}\text { Expectativa de } \\
\text { Autoeficácia }\end{array}$} & 3. Ciências Contábeis não foi minha primeira opção de curso. \\
\hline & $\begin{array}{l}\text { 12. Conheci o curso de Ciências Contábeis por meio do meu curso técnico } \\
\text { profissionalizante ou superior anterior. }\end{array}$ \\
\hline & 14. Não possuo habilidades para ser um contador de sucesso. \\
\hline & 15. Escolhi cursar Ciências Contábeis porque gosto de matemática. \\
\hline & 19. Não realizei pesquisa sobre o curso antes do processo seletivo \\
\hline \multicolumn{2}{|l|}{ Fatores externos } \\
\hline \multirow{2}{*}{ Empregabilidade } & 4. Escolhi o curso de Ciências Contábeis por ter mercado de trabalho aquecido. \\
\hline & 18. Já estava trabalhando na área quando decidi cursar Ciências Contábeis. \\
\hline \multirow{3}{*}{$\begin{array}{l}\text { Influência } \\
\text { pais/pares }\end{array}$} & 5. Meus pais me influenciaram a cursar Ciências Contábeis. \\
\hline & 11. Meus pais não gostaram da minha escolha profissional. \\
\hline & $\begin{array}{l}\text { 13. Um contador conhecido (que não são meus pais) me incentivou a cursar Ciências } \\
\text { Contábeis. }\end{array}$ \\
\hline \multirow{2}{*}{$\begin{array}{c}\text { Fatores } \\
\text { socioeconômicos }\end{array}$} & 9. A Contabilidade é uma profissão mais próspera para o gênero masculino. \\
\hline & $\begin{array}{l}\text { 10. Escolhi cursar Ciências Contábeis por não ter condições financeiras de fazer o curso } \\
\text { que gostaria. }\end{array}$ \\
\hline \multirow{6}{*}{$\begin{array}{c}\text { Planejamento da } \\
\text { carreira }\end{array}$} & 7. Contabilidade é uma profissão que me trará autonomia. \\
\hline & 8. Comecei a planejar minha carreira assim que escolhi o curso. \\
\hline & 2. Conheci o curso de Ciências Contábeis durante o vestibular. \\
\hline & 16. Desejo trabalhar numa empresa que me traga crescimento profissional. \\
\hline & 17. Desejo uma carreira que me traga flexibilidade de horários e de tarefas. \\
\hline & $\begin{array}{l}\text { 20. Tenho uma profissão diferente da contábil e resolvi fazer o curso de Ciências } \\
\text { Contábeis para complementar meus objetivos de carreira. }\end{array}$ \\
\hline
\end{tabular}

Fonte: Peleias, Nunes e Carvalho (2017, p.49). 
Conforme o exposto, Peleias, Nunes e Carvalho (2017) classificaram os 20 (vinte) fatores contribuidores da escolha pela graduação em Ciências Contábeis em externos ou internos. Configurando-se como fatores internos, aqueles relacionados a clareza de autoconhecimento e a expectativa de autoeficácia, a subdivisão destes foi feita em variáveis relacionadas ao indivíduo, neste caso, ao estudante de contabilidade. Os fatores externos, correspondem aos temas inerentes a empregabilidade, influência de pais/pares, socioeconômicos e planejamento de carreira, a subdivisão foi feita considerando variáveis relacionados ao ambiente que rodeia o estudante de contabilidade.

Neste estudo, ao revisar as pesquisas sobre o tema, foi possível ampliar as variáveis utilizadas pelos pesquisadores da área, conforme a listagem a seguir:

1. Escolhi cursar Ciências Contábeis por ser uma pessoa criativa (HSIAO; NOVA, 2016).

2. A profissão me permite atuar e especializar em diferentes áreas/segmentos da empresa (PINHEIRO; SANTOS, 2010; MARQUES; SALVIANO; SILVA, 2016; SOUZA; DURSO, 2018).

3. Pretendo administrar a empresa da minha família (PINHEIRO; SANTOS, 2010; MARQUES; SALVIANO; SILVA, 2016).

4. Escolhi cursar Ciências Contábeis porque pretendo trabalhar com pessoas e contribuir com a sociedade (HSIAO; NOVA, 2016).

5. Escolhi cursar Ciências Contábeis porque a imagem da instituição é boa tradição, experiência, credibilidade, qualidade (MARQUES; SALVIANO; SILVA, 2016; RABABAH, 2016).

6. É um curso que se mantém atualizado com as evoluções de mercado (HSIAO; NOVA, 2016; MARQUES; SALVIANO; SILVA, 2016).

7. É um curso que me prepara para abrir minha própria empresa (PINHEIRO; SANTOS, 2010).

8. Amplia minha cultura geral e meu desenvolvimento intelectual (PINHEIRO; SANTOS, 2010; MARQUES; SALVIANO; SILVA, 2016).

9. Escolhi cursar Ciências Contábeis porque a profissão me proporciona segurança ou estabilidade profissional (HSIAO; NOVA, 2016).

A Tabela 2 apresenta 30 (trinta) frases constituindo-se nas variáveis deste estudo. Foram agrupadas 20 (vinte) variáveis abordadas na pesquisa de Peleias, Nunes e Carvalho (2017), 09 (nove) variáveis destacas na listagem anterior e, com o propósito de ampliar o debate, também foi incluída a variável: escolhi cursar Ciências Contábeis porque pretendo seguir a carreira pública, prestar concurso público”. Desta forma, esta pesquisa abordou 30 (trinta) variáveis transformadas em pequenas frases que possibilitaram a avaliação dos 
discentes sobre os fatores que contribuíram para a escolha da graduação em Ciências Contábeis.

Tabela 2 Fatores determinantes da escolha pelo curso de Graduação em Ciências Contábeis

\begin{tabular}{|c|c|}
\hline 1. Tenho vocação. & 2. Pretendo trabalhar com pessoas e contribuir com a sociedade. \\
\hline 3. A profissão proporciona Status. & $\begin{array}{l}\text { 4. A contabilidade é uma profissão mais próspera para o gênero } \\
\text { masculino. }\end{array}$ \\
\hline 5. Sou uma pessoa criativa. & 6. Não tenho condições financeiras de fazer o curso que gostaria. \\
\hline 7. Não foi minha primeira opção de curso. & 8. Imagem da instituição. \\
\hline 9. Curso técnico ou superior anterior. & 10.É um curso que se mantém atualizado. \\
\hline $\begin{array}{l}\text { 11.Não possuo habilidades para ser um contador de } \\
\text { sucesso. }\end{array}$ & 12.Contabilidade é uma área que me trará autonomia. \\
\hline 13.Gosto de matemática. & 14.Me prepara para abrir minha própria empresa. \\
\hline 15.Não realizei pesquisa sobre o curso. & 16.Amplia minha cultura geral e meu desenvolvimento intelectual. \\
\hline 17.Mercado de trabalho aquecido. & 18.Planejei minha carreira assim que escolhi o curso. \\
\hline 19.Já estava trabalhando na área. & 20.Conheci o curso de contábeis durante o vestibular. \\
\hline $\begin{array}{l}\text { 21.Possibilidades de atuar e especializar em diferentes } \\
\text { áreas/segmentos da empresa. }\end{array}$ & $\begin{array}{l}\text { 22.Desejo trabalhar numa empresa que me traga crescimento } \\
\text { profissional. }\end{array}$ \\
\hline 23.Meus pais me influenciaram. & 24.A profissão me proporciona segurança ou estabilidade profissional. \\
\hline 25.Meus pais não gostaram da minha escolha. & 26.A carreira me proporciona flexibilidade de horários e de tarefas. \\
\hline $\begin{array}{l}\text { 27.Contador conhecido (que não são meus pais) me } \\
\text { incentivou. }\end{array}$ & $\begin{array}{l}\text { 28.Resolvi fazer o curso de Ciências Contábeis para complementar } \\
\text { meus objetivos de carreira. }\end{array}$ \\
\hline 29.Pretendo administrar a empresa da família. & 30.Pretendo trabalhar com pessoas e contribuir com a sociedade. \\
\hline
\end{tabular}

Fonte: Baseado em Alanezi et al. (2016); Chen, Jones e Mcintyre (2008), Dalci et al. (2013), Durgut e Pehlivan (2019), Germanou, Hassall e Tournas (2009), Grabowski (2019), Indriani e Murti (2018), Hsiao e Nova (2016), Khalid et al. (2018), Lopens e Meurer (2019), Marques, Salviano e Silva (2016), Ng et al. (2017), Peleias, Nunes e Carvalho (2017), Pinheiro e Santos (2010), Politelo, Manfroi e Cunha (2013), Pratama (2017), Souza e Durso (2018), Srirejeki, Supeno e Faturahman (2019), Thing e Jalaludin (2018), Uyar, Güngörmüş e Kuzey (2011), Umar (2014), Wally-Dima (2013).

A Tabela 2 demonstra diversos fatores determinantes na escolha da graduação em Ciências Contábeis. Vale frisar a necessidade de estudos como este, cujo propósito contribui para o levantamento dos motivadores articuladores do mecanismo de: formulação do projeto pedagógico dos cursos, da atividade dos gestores mediante a administração do curso, dos melhores caminhos para acolher e dar suporte a formação dos estudantes.

Reunidos os fatores motivadores da escolha da profissão contábil, no item que segue é apresentado o locus de pesquisa, os participantes da pesquisa, os detalhes na elaboração do instrumento de coleta de dados, além dos cuidados com a coleta, os procedimentos de validação e credibilidade utilizados neste estudo.

\section{PROCEDIMENTOS METODOLÓGICOS}

\subsection{PROCEDIMENTOS, COLETA DE DADOS E CARACTERIZAÇÃO DA AMOSTRA}

A coleta de dados ocorreu por meio da aplicação de questionário estruturado, a partir do qual o respondente assinalou de forma nivelada a resposta disponível mais cabível. O questionário foi composto por três blocos e adaptado a partir do estudo de Peleias, Nunes e 
Carvalho (2017), cuja investigação pautou-se no levantamento das informações sobre os fatores determinantes na escolha do curso de Ciências Contábeis por estudantes de instituições de ensino superior particulares na cidade de São Paulo.

O primeiro bloco contempla o perfil do respondente e o consentimento em participar do estudo. Na sequência, a segunda parte teve como objetivo levantar características dos respondentes, como: sexo, idade, local de residência, período de matrícula no curso, faixa salarial da família, escola (pública/privada) onde cursou o ensino médio e disciplinas (exatas, humanas/sociais e biológicas) de preferência. A caracterização dos respondentes, normalmente tem ocorrido em estudos como este para apresentar, no conjunto, uma breve descrição da amostra de pesquisa. Além disso, serve para verificar se há correlações divergentes entre as características dos entrevistados, como por exemplo, se os fatores que constituem a escolha pela graduação em Ciências Contábeis são os mesmos para os discentes de origem da escola pública, quando comparados com os de escolas privadas.

O último bloco do questionário buscou conhecer a avaliação dos respondentes em relação a situações que envolvem os fatores que constituem a escolha pela graduação de Ciências Contábeis. Diante das afirmativas apresentadas no questionário, considerou-se uma escala Likert de cinco pontos com variação de 1 (um) a 5 (cinco) para que o respondente avaliasse a importância da variável na escolha pela graduação em Ciências Contábeis.

Para a obtenção dos dados, o primeiro contato adveio junto a coordenação do curso de graduação em Ciências Contábeis de uma instituição pública do Estado de Mato Grosso do Sul, com a aprovação para a aplicação do questionário e o levantamento do número de discentes, correspondendo 215 (duzentos e quinze) alunos. Priorizou-se os respondentes conforme a sua disponibilidade de participação, no período de 03 a 28 de junho de 2019.

A amostra da pesquisa ficou composta por 123 (cento e vinte e três) respondentes e o perfil dos entrevistados está sistematizado na Tabela 3.

A amostra da pesquisa compôs-se de 58 (cinquenta e oito) sujeitos do sexo masculino, $47,2 \%$ e 65 (sessenta e cinco) do sexo feminino, 52,8\% (cinquenta e dois) do total de respondentes. Grande parte dos sujeitos componentes da amostra tem renda familiar de até R\$ 3.940,00 e a maioria dos graduandos preferem as disciplinas da área de exatas. A maior parte dos respondentes estão matriculados nos primeiros semestres do curso e são oriundos de escolas públicas. Em síntese, 65 (sessenta e cinco), 52,8\%, residem em Três Lagoas no Mato Grosso do Sul e 55 (cinquenta e cinco), 44,7\% dos respondentes, residem no interior do estado de São Paulo. 
Tabela 3 Perfil da amostra

\begin{tabular}{|c|c|c|c|}
\hline Características & Detalhes & Frequências & $\% s$ \\
\hline \multirow{2}{*}{ Gênero } & Masculino & 58 & $47,2 \%$ \\
\hline & Feminino & 65 & $52,8 \%$ \\
\hline \multirow{5}{*}{ Renda familiar } & Até R\$ $1.576,00$ & 35 & $28 \%$ \\
\hline & De $\mathrm{R} \$ 1.576,01$ a $\mathrm{R} \$ 2.364,00$ & 32 & $26 \%$ \\
\hline & De R\$ 2.364,01 a R\$ 3.940,00 & 26 & $21 \%$ \\
\hline & De R\$ 3.940,01 a R\$ 7.880,00 & 22 & $18 \%$ \\
\hline & Acima de $\mathrm{R} \$ 7.880,01$ & 8 & $7 \%$ \\
\hline \multirow{2}{*}{$\begin{array}{l}\text { Preferências de } \\
\text { disciplinas }\end{array}$} & Exatas & 76 & $62 \%$ \\
\hline & Humanas e ou sociais & 47 & $38 \%$ \\
\hline \multirow{8}{*}{ Semestre do curso } & Primeiro & 45 & $36,6 \%$ \\
\hline & Segundo & 1 & $1 \%$ \\
\hline & Terceiro & 29 & $24 \%$ \\
\hline & Quarto & 3 & $2 \%$ \\
\hline & Quinto & 27 & $22 \%$ \\
\hline & Sexto & 12 & $10 \%$ \\
\hline & Sétimo & 5 & $4 \%$ \\
\hline & Oitavo & 1 & $1 \%$ \\
\hline \multirow{3}{*}{ Ensino médio } & Escola pública & 93 & $76 \%$ \\
\hline & Escola particular & 22 & $18 \%$ \\
\hline & Escola pública e particular & 8 & $7 \%$ \\
\hline \multirow{3}{*}{ Residência } & Três Lagoas & 65 & $52,8 \%$ \\
\hline & Outro município de MS & 3 & $2,4 \%$ \\
\hline & Município de SP & 55 & $44,7 \%$ \\
\hline
\end{tabular}

Fonte: Dados da pesquisa (2020).

Tabela 4 Componentes da pesquisa

\begin{tabular}{cl}
\hline \multicolumn{1}{c}{ Itens } & \multicolumn{1}{c}{ Descrição } \\
\hline $\begin{array}{c}\text { Revisão teórica e } \\
\text { empírica }\end{array}$ & $\begin{array}{l}\text { A revisão das pesquisas empíricas teve foco na abordagem do tema: fatores } \\
\text { determinantes na escolha da graduação em Ciências Contábeis. }\end{array}$ \\
\hline População & $\begin{array}{l}\text { Corresponde a 215 (duzentos e quinze) alunos matriculados no curso de Graduação } \\
\text { em Ciências Contábeis em uma universidade pública federal, situada no interior do } \\
\text { estado de Mato Grosso do Sul. }\end{array}$ \\
\hline Amostra & $\begin{array}{l}\text { Por acessibilidade, sendo 123 (cento e vinte) respondentes do questionário de } \\
\text { pesquisa. }\end{array}$ \\
\hline Instrumento de pesquisa & $\begin{array}{l}\text { Questionário de pesquisa adaptado dos estudos de Peleias, Nunes e Carvalho } \\
\text { (2017). }\end{array}$ \\
\hline Validação & Aplicado a 10 (dez) alunos do curso de Administração, devidamente matriculados. \\
\hline Coleta dos dados & Ocorreu entre os dias 03 a 28 de junho de 2019. \\
\hline Organização dos dados tos tos & $\begin{array}{l}\text { Após a coleta dos questionários os dados foram tabulados em planilhas excel. As } \\
\text { informações foram obtidas pelo software SPSS, versão 22. }\end{array}$ \\
\hline Análise dos dados & $\begin{array}{l}\text { Para validar e proporcionar credibilidade ao estudo realizou-se a análise fatorial, } \\
\text { com os seguintes procedimentos: análise da confiabilidade do conjunto total de } \\
\text { dados; verificação do índice de significância; compreensão das comunalidades; } \\
\text { aplicação do Alfa de Cronbach e do teste KMO. }\end{array}$ \\
\hline
\end{tabular}

Fonte: Adaptado de Creswell (2010).

Este estudo caracteriza-se como survey (Creswell, 2010). A abordagem do problema é quantitativa e utilizou-se da técnica denominada análise fatorial para tratamento e compreensão dos dados coletados, em razão da possibilidade de reunir os fatores contribuintes da escolha pela graduação em Ciências Contábeis e, inclusive, a referida técnica proporciona 
a reunião destes fatores em componentes, nuance, a qual pode contribuir com a temática ao reunir o conjunto de fatores em poucos itens. Sob esta égide, adotou-se os seguintes componentes para atender aos objetivos propostos e promover o direcionamento da pesquisa:

Diante da descrição dos procedimentos metodológicos, na próxima sessão apresenta-se a análise dos dados.

\section{RESULTADOS}

\subsection{ANÁLISE FATORIAL}

Para a análise dos dados, realizou-se a análise fatorial que segundo Hair, Black, Babin, Anderson e Tathan $(2009$, p.107) trata-se de um método capaz de fornecer ao pesquisador "uma clara compreensão sobre quais variáveis podem atuar juntas e quantas variáveis podem realmente ser consideradas como tendo impacto na análise".

Após a coleta, foi estabelecido o tratamento dos dados, a partir dos quais se verificou a inexistência de outliers e não houve a necessidade de incluir na análise o preenchimento da média para os valores ausentes. Desta forma, a análise com todas as variáveis do estudo, os 30 (trinta) fatores, apresentou os seguintes índices, conforme Tabela 5.

Tabela 5 Resultado dos testes de consistência das 30 (trinta) variáveis

\begin{tabular}{|c|c|c|c|}
\hline Alpha de Cronbach & Esfericidade de Bartlett & KMO & \% Variância explicada \\
\hline & Sig. & & \\
\hline 0,648 & 0,00 & 0,636 & 67,244 \\
\hline
\end{tabular}

Fonte: Dados da pesquisa (2020).

Os dados foram considerados confiáveis por meio da aplicação do teste Alfa de Cronbach, a partir do qual se obteve o índice de 0,648. Em pesquisas de natureza exploratória, Hair et al. (2009) afirma que este índice quando superior a 0,60 apresenta-se como aceitável. Para análise da adequação da amostra utilizou-se do teste KMO que apresentou o resultado de 0,636. Para Marôco (2010), o KMO acima de 0,50 representa alta capacidade de fatorabilidade. Também, foi realizado o Teste de Esfericidade de Bartlett's, com o resultado de significância de 0,00 , o que para Hair et al. (2009) rejeita a probabilidade de que a matriz populacional seja idêntica.

A análise dos dados permite constatar que o conjunto de variáveis explicam a variância de 67,244\% dos fatores contribuintes dos acadêmicos optarem por cursar a graduação em Ciências Contábeis. Vale ressaltar que as recomendações de Hair et al. (2009, p. 115), sugerem que o número de fatores deve ser "suficiente para atender um percentual 
especificado de variância explicada, geralmente de $60 \%$ ou mais". Contudo, as variáveis mantidas na análise foram aquelas que, além de atenderem as recomendações de Hair et al. (2009), em relação ao índice de comunalidade acima de 0,50, também, enquadraram-se nas orientações dos valores de curtose e assimetria, que devem ficar entre \pm 3 .

Desta forma, obteve-se algumas variáveis excluídas, em decorrência de não atenderem aos padrões de curtose, assimetria ou comunalidades. São elas: diferentes áreas, meus pais influenciaram, contribuição social, gênero masculino, imagem da instituição, curso atualizado, status, influência técnica de profissionais, por não possuir habilidades, não pesquisei, estava trabalhando, contador conhecido, empresa da família, planejar carreira, flexibilidade na carreira, complementar carreira, concurso público, pessoa criativa, matemática, mercado de trabalho.

Mantiveram-se no estudo, apenas as variáveis significativas. Este estudo também se utilizou da redução de fatores por meio do método de extração dos componentes principais, viabilizada pela técnica de rotação varimax para obtenção dos índices. Assim, observa-se pequena redução no Alpha de Cronbach, porém, os demais coeficientes melhoraram, principalmente, o percentual de variância explicada que passou a ser de 78,548, conforme exposição na Tabela 6.

Tabela 6 Resultado dos testes de consistência das 10 (dez) variáveis

\begin{tabular}{cccc}
\hline Alpha de Cronbach & Esfericidade de Bartlett & \multirow{2}{*}{ KMO } & \multirow{2}{*}{ \% Variância explicada } \\
\cline { 2 - 2 } & Sig. & & \\
\hline 0,612 & 0,00 & 0,649 & 78,548 \\
\hline
\end{tabular}

Fonte: Dados da pesquisa (2020).

Desta forma, as variáveis foram reunidas em 5 (cinco) componentes ou categorias, com autovalor superior a 1 e o percentual de variância explicada de 78,548. Conforme mencionado, os referidos índices atendem aos padrões estabelecidos por Hair et al. (2009).

As recomendações de Hair et al. (2009, p. 115), sugerem que o número de fatores deve ser "suficientes para atender um percentual especificado de variância explicada, geralmente de $60 \%$ ou mais". Os resultados obtidos permitem inferir que os 5 (cinco) componentes explicam $78,548 \%$ dos fatores que constituem a escolha pela graduação em Ciências Contábeis na perspectiva dos alunos respondentes.

Os resultados permitem considerar que os acadêmicos esperam que a conclusão da graduação em Ciências Contábeis possa proporcionar independência as suas vidas: autonomia, condições para abrir a própria empresa, desenvolvimento intelectual e estabilidade 
profissional. Os pais dos graduandos, por sua vez, não aprovaram a escolha da graduação, não viram a escolha sob a mesma ótica dos filhos que tomaram conhecimento do curso durante o processo de vestibular. Além dessas considerações, é preocupante o fato de o resultado não apresentar variáveis relacionadas aos aspectos empregabilidade e econômicos como relevantes para a escolha da graduação em Ciências Contábeis. Uma vez que, estes itens foram evidenciados em pesquisas desta natureza. Além de que, a graduação, ou seja, a qualificação sempre tem como propósito obter reconhecimento da sociedade, seja, por meio de emprego ou oferta de bons salários.

Tabela 7 Fatores explicativos do modelo utilizado

\begin{tabular}{ccccc}
\hline Componentes & \multicolumn{3}{c}{ Valores próprios iniciais } & $\begin{array}{c}\text { Somas rotativas } \\
\text { \% cumulativa }\end{array}$ \\
\hline \multicolumn{7}{c}{ Total } & Variância & Cumulativa & \\
\hline 2 & 2,667 & 26,668 & 26,668 & 22,489 \\
\hline 3 & 1,932 & 19,322 & 45,990 & 41,519 \\
\hline 4 & 1,187 & 11,867 & 57,857 & 56,743 \\
\hline 5 & 1,061 & 10,611 & 68,468 & 78,548 \\
\hline 6 & 1,008 & 10,080 & 78,548 & \\
\hline 7 &, 563 & & \\
\hline 8 &, 521 & & \\
\hline 9 &, 408 & & \\
\hline 10 &, 344 & & \\
\hline
\end{tabular}

Fonte: Dados da pesquisa (2020).

Os detalhes dos 5 (cinco) componentes foram apresentados na Tabela 8.

Tabela 8 Fatores motivadores da escolha pela graduação em Ciências Contábeis

\begin{tabular}{|c|c|c|c|c|c|}
\hline \multicolumn{6}{|c|}{ Motivos da escolha pela graduação em contabilidade } \\
\hline \multirow[b]{2}{*}{ Fatores } & \multicolumn{5}{|c|}{ Componentes } \\
\hline & 1 & 2 & 3 & 4 & 5 \\
\hline Vocação & & $-0,826$ & & & \\
\hline Não foi a primeira opção & & 0,851 & & & \\
\hline Meus pais não gostaram & & & & 0,937 & \\
\hline Não ter condições financeira & & 0,670 & & & \\
\hline Autonomia & 0,864 & & & & \\
\hline Própria empresa & 0,815 & & & & \\
\hline Desenvolvimento intelectual & 0,844 & & & & \\
\hline Conheci durante o vestibular & & & & & 0,983 \\
\hline Crescimento profissional & & & 0,817 & & \\
\hline Estabilidade & & & 0,866 & & \\
\hline
\end{tabular}

Fonte: Dados da pesquisa (2020).

A resposta para o objetivo norteador desta pesquisa, a saber: identificar os fatores que constituem a escolha pela graduação de Ciências Contábeis, sob a ótica de discentes de uma Instituição de Ensino Superior Federal localizada no Estado do Mato Grosso do Sul, encontra- 
se mensurada na Tabela 8. A partir dos dados nela expressos, os respondentes acreditam que o conjunto dos 10 (dez) fatores reunidos em 5 (cinco) componentes são responsáveis por $78,548 \%$ dos aspectos que contribuem com a escolha pela graduação em Ciências Contábeis.

Estes resultados, permitiram a esta pesquisa apresentar os fatores determinantes da escolha pela graduação em Ciências Contábeis, sob a ótica de discentes eleitos para este estudo. Para fins didáticos, os mesmos foram reunidos em 5 (cinco) componentes e denominadas, como:

- Componente 1 (um): responsável por 26,668\% das escolhas, é formado por: autonomia, própria empresa e desenvolvimento intelectual. Diante dos fatores reunidos neste item, foi possível observar que os principais fatores na escolha pela graduação em Ciências Contábeis relacionam-se com a procura por independência. Ou seja, os discentes querem conhecimento suficiente para criar a própria empresa. Infere-se que após a graduação, os futuros contadores planejam a independência profissional, ao abrirem a própria empresa.

- Categoria 2 (dois): explica 19,322\% dos motivos os quais contribuem com a escolha e reuni as variáveis: vocação, não foi a primeira opção e não ter condições financeiras. Por meio destes fatores, conclui-se que apesar de aspectos sociais negativos como não ter condições financeira e não ser a primeira opção pretendida pelo graduando, os respondentes afirmaram ter vocação para a profissão contábil. Assim, diante das possibilidades o curso de Ciências Contábeis apresenta-se como o mais atrativo.

- Componente 3 (três): apresentou percentual de explicação dos motivos que contribui com a escolha pela profissão de $11,867 \%$ e foi formado pelas variáveis crescimento profissional e estabilidade. Este aspecto permitiu constatar que o exercício da profissão contábil pode proporcionar estabilidade no mercado de trabalho. O exercício da profissão contábil contribui com a estabilidade profissional.

- Componente 4 (quatro): tem condições de explicar 10,611\% e foi formado apenas pela variável meus pais não gostaram da escolha pela graduação em Ciências Contábeis. Isso explica que os pais tinham preferência por outra profissão para o filho, porém, pode-se inferir que apesar de não ser o desejo dos pais, os mesmos, não se opuseram.

- Componente 5 (cinco): tem possibilidade de 10,080\% do contexto pesquisado e apresentou apenas o fator conheci o curso durante o vestibular. O que demonstra falta de conhecimento da profissão contábil pelos discentes, ou seja, tomaram conhecimento só quando iniciaram o processo de vestibular.

Os três primeiros componentes foram denominados como: planejar, possibilidade e estabilidade. Estes três itens juntos explicam 57,857\% dos fatores contribuintes pela graduação em Ciências Contábeis. Vale ressaltar que, os referidos componentes foram 
formados por variáveis as quais podem ser consideradas na maioria extrínsecas, em detrimento das intrínsecas.

\subsection{ANÁLISE E DISCUSSÃO DOS DADOS}

Em relação às variáveis: "não foi minha primeira opção"; "meus pais não gostaram" e "não ter condições financeiras", foi possível identificar na literatura que tais variáveis não apresentaram significância ao serem testadas no estudo de Peleias, Nunes e Carvalho (2017), e as três variáveis são mencionadas, neste estudo, como determinantes na escolha da graduação para os alunos do locus eleito par esta pesquisa. Isso demonstra, que os respondentes optaram pelo curso por não ter condições financeiras para cursarem outra graduação.

A amostra também apontou como as variáveis "autonomia" e o "desenvolvimento intelectual" influenciaram na escolha dos acadêmicos em Ciências Contábeis. Este resultado vai ao encontro dos estudos de Pinheiro e Santos, (2010), Marques, Salviano e Silva (2016), Peleias, Nunes e Carvalho (2017). Por meio deles é possível entender que a imagem do curso na sociedade constitui-se pela possibilidade de proporcionar desenvolvimento intelectual e autonomia, fato que reflete diretamente na escolha pela carreira.

Outra consideração manifesta é o fato dos discentes esperarem que a conclusão da graduação em Ciências Contábeis possa proporcionar independência. Eles creem que a graduação proporcionará autonomia e desenvolvimento intelectual às suas vidas. Assim, este estudo corrobora com as pesquisas de Pinheiro e Santos, (2010), Marques, Salviano e Silva (2016). Apesar de não ser a primeira opção no vestibular, os alunos constataram, ao cursar a graduação de Ciências Contábeis, uma vocação para a profissão contábil, mesmo não conhecendo a graduação ao prestarem o vestibular e os pais não ficaram satisfeitos pela escolha feita. No estudo de Peleias, Nunes e Carvalho (2017), a vocação foi uma das variáveis determinantes para a escolha da profissão. Nesta pesquisa ela foi uma constatação proveniente do contato com o curso por parte do acadêmico.

Outro aspecto verificado: ao escolher cursar Ciências Contábeis, o aluno influencia-se pelo desejo de abrir a própria empresa, o que mostra a imagem positiva do curso no meio empreendedor. Para Pinheiro e Santos (2010), essa visão, dos alunos diante da graduação, evidencia que tal variável é um fator determinante na escolha, demonstrando o quanto os alunos veem no curso uma porta que se abre para ascensão social. 
Os testes apresentaram a variável "ao cursar a graduação em Ciências Contábeis espero obter estabilidade na profissão" como determinante na amostra obtida, esse resultado encontra-se registrado na pesquisa de Hsiao e Casa Nova (2016), nela os autores abordam os desafios da geração $\mathrm{Y}$ na escolha da carreira. Também se obteve como resultado desta pesquisa, o fato de que o fator obter crescimento profissional foi determinante na escolha da profissão, dado constatado no estudo de Peleias, Nunes e Carvalho (2017), quando pesquisaram estudantes de Instituições de Ensino Superior da cidade de São Paulo.

Apesar das variáveis significantes, enfatiza-se um fato preocupante em relação às variáveis relacionadas à empregabilidade e aos fatores econômicos: elas não se apresentaram como relevantes na motivação pela escolha da carreira na área contábil. No entanto, variáveis relacionadas a empregabilidade já foram evidenciadas como determinantes para a escolha da profissão contábil em estudos de Chen, Jones e Mcintyre (2008), Cavalcante (2009), Uyar, Güngörmüş e Kuzey (2011), Umar (2014), Marques, Salviano e Silva (2016), Alanezi, Alfraih, Haddad e Altaher (2016), Peleias, Nunes e Carvalho (2017), Souza e Durso (2018). Simultaneamente, variáveis relacionadas aos fatores econômicos tiveram resultados significativos nas pesquisas de Hsiao e Casa Nova (2016) e de Marques, Salviano e Silva (2016).

Diante da discussão dos dados obtidos, pode-se dizer que os discentes ao cursar Ciências Contábeis não consideram os aspectos de empregabilidade e econômicos determinantes para a referida escolha. No entanto, ressalva-se que apesar de preocupante, este fato pode não ser estritamente uma característica da área contábil, devido à crise que o país atravessa. Assim, a falta de oportunidades na área contábil pode ser motivada pela crise econômica enfrentada pelo Brasil nos últimos anos.

Por fim, enfatiza-se que o primeiro componente explica $26,668 \%$ dos motivos os quais contribuem com a escolha pela graduação em Ciências Contábeis e reuniu variáveis como: autonomia, própria empresa e desenvolvimento intelectual. Desta forma, os graduandos consideram que o curso oferece condições de independência profissional, ou seja, o conhecimento adquirido na graduação proporcionará condições para criarem a própria empresa.

\section{CONCLUSÃO}

Este estudo objetivou identificar os fatores constitutivos da escolha do curso de Ciências Contábeis, sob a ótica de discentes de uma Instituição de Ensino Superior Federal, 
situada no interior do Estado de Mato Grosso do Sul. Para tanto adaptou-se o instrumento de coleta de dados de Peleias, Nunes e Carvalho (2017), obtendo uma amostra de 123 respondentes.

Os resultados da pesquisa apontaram que os fatores que mais influenciam na escolha do curso de Ciências Contábeis, segundo os entrevistados, resumem-se em: vocação; não foi a primeira opção no vestibular; não ter condições financeiras; autonomia; abertura da própria empresa; desenvolvimento intelectual; interesse pela graduação em contabilidade ocorrido durante o vestibular; crescimento profissional e estabilidade.

Expostas as variáveis significativas, infere-se que na perspectiva de discentes, alunos de Ciências Contábeis da Instituição Federal de Ensino Superior, localizada no Estado do Mato Grosso do Sul, norteiam sua escolha por um conjunto de variáveis reunidas em 5 (cinco) componentes, cuja representação possui um percentual de variância explicada de $78,548 \%$ do contexto. Considera-se que os 10 (dez) fatores, reunidos dentro destes 5 (cinco) nichos distintos, são os que contribuem com a escolha pela graduação em Ciências Contábeis.

Os três primeiros componentes, desta pesquisa, foram denominados, respectivamente, como: planejar, possibilidade e estabilidade. Estes três itens juntos explicam $57,857 \%$ dos fatores contribuintes pela graduação em Ciências Contábeis. Vale ressaltar que os referidos componentes foram formados por variáveis as quais podem ser consideradas na maioria extrínsecas, em detrimento das intrínsecas.

Enfatiza-se o fato preocupante em relação às variáveis relacionadas a empregabilidade e aos fatores econômicos, por não se apresentaram como relevantes na motivação pela escolha da carreira na área contábil. Isso demonstra que este resultado pode ser motivado pela crise econômica enfrentada pelo Brasil nos últimos anos, o que contribui com a falta de empregos na área contábil.

As limitações dessa pesquisa vinculam-se a questão da amostra, já que o estudo contemplou apenas um local, entre as diversas universidades federais do Brasil. Como contribuições, pode-se dizer que ao reunir o conjunto de fatores, identifica-los e classificá-los em sua contribuição com a escolha pela graduação em Ciências Contábeis, sob a ótica dos estudantes, foi possível identificar como estes alunos têm compreendido a profissão. Além de abrir o precedente para se ponderar quais as possíveis lacunas de saberes devem ser preenchidas ou mesmo ampliadas para proporcionar conhecimento das variáveis pelas quais os futuros profissionais podem se sentir motivados e contribuir com possíveis melhorias a formação dos profissionais nesta área de formação. 
Como sugestão e contribuição para estudos futuros, sugere-se aplicar a pesquisa em universidades privadas, comunitárias e públicas. E ainda por diversas regiões geográficas, para investigar se os fatores motivadores na escolha do curso diferem por tipo de universidade e região. Observar as diferenças e semelhanças apresentadas a partir de locus de pesquisa diferentes.

\section{REFERÊNCIAS}

ALANEZI, F.S., ALFRAIH, M.M., HADDAD, A.E., ALTAHER, N. A. Factors Influencing Students' Choice of Accounting as a Major: Further Evidence from Kuwait. Global Review of Accounting and Finance, 7(1), 165-177, 2016.

CAVALCANTE, C. H. L. Percepção dos alunos iniciantes e concluintes do Curso de Ciências Contábeis sobre a profissão contábil. Revista Brasileira de Contabilidade. Conselho Federal de Contabilidade, 51p, 2009.

CEPA, M.C.R. Percepções dos alunos e fatores de influência sobre a escolha da Contabilidade como área de estudo Trabalho. Dissertação de Mestrado em Contabilidade. Universidade do Minho - Escola de Economia e Gestão, Portugal, 2015.

CHEN, C., JONES, K. T., MCINTYRE, D. D. Analyzing the Factors Relevant to Students' Estimations of the Benefits and Costs of Pursuing an Accounting Career. Accounting Education: an international journal, 17:3, 313-32, 2008.

CRESWELL, J. W. O projeto de pesquisa. Porto Alegre: Artmed, 2010.

DALCI, I., ARASLI, H., TÜMER, M., BARADARANI, S. Factors that influence Iranian students' decision to choose accounting major. Journal of Accounting in Emerging Economies, 3(2), 145-163, 2013.

DURGUT, M., PEHLIVAN, A. Analysis of factors that affect the job choice of accounting students. Karadeniz Teknik Üniversitesi Sosyal Bilimler Enstitüsü Sosyal Bilimler Dergisi, Y11: 9 Sayı: 17/Haziran, 2019.

GERMANOU, E., HASSALL, T., TOURNAS, Y. Students' perceptions of accouting profession: work value approach. Asian Review of Accounting, 17(2), 136-148, 2009.

GRABOWSKI, R. Student perspective on skills needed in the accounting profession: a review of studies. Journal of Management and Financial Sciences, 36, 123-138, 2019.

HAIR, F.J., BLACK, W. C., BABIN, B., ANDERSON, R. E., TATHAN, R. L. Análise multivariada de dados. Porto Alegre: Bookman, 2009.

HSIAO, J., \& NOVA, S. P. C. C. Abordagem Geracional dos Fatores que Influenciam a Escolha de Carreira em Contabilidade. Revista Contabilidade \& Finanças - USP, 27(72), 393-407, 2016. 
INDRIANI, E, MURTI, N, W. Patterns and determinants of Indonesian accounting students' career choice. Journal of Economics, Business, and Accountancy Ventura, 21(2), 177 $186,2018$.

INEP. Instituto Nacional de Estudos e Pesquisas Educacionais Anísio Teixeira. Censo 2018. Disponível em: < http://portal.mec.gov.br/docman/setembro-2018-pdf/97041-apresentac-a-ocenso-superior-u-ltimo/file>. Acesso: 10 Junho de 2019.

KHALID, F. M., RAUF, F.H.A., FUAD, N.F.A., SAAIBON, S., ASRI, N.A.M. SHAROM, N.D. Factors Influencing High School Students to Major in Accounting. Global Business and Management Research: An International Journal, 10(3), 2018.

LOPENS, I. F., \& MEURER, A. M. Autoeficácia, Elementos Priorizados na Prospecção de Carreira e Comportamento Acadêmico: Análise dos Estudantes de Ciências Contábeis das IES Públicas. Revista de Educação e Pesquisa em Contabilidade (REPeC), 13(1), 46-67, 2019.

MARÔCO, J. Análise de equações estruturais. Perô Pinheiro: ReportNumber, 2010.

MARQUES, V. A., SALVIANO, R. A. G., SILVA, C. E. S. O que importa na escolha pelo curso de ciências contábeis? Uma análise a partir das teorias da motivação. Revista de Contabilidade da UFBA, 10(3), 176 - 197, 2016.

NG, L. C., CHONG, H. O., H’NG, C. K., KHOR, P. H., NG, S. V. Fatores que afetam as preferências de seleção de trabalho de estudantes de contabilidade em universidades da Malásia. Tese de doutorado, Universiti Tunku Abdul Rahman, Malásia, 2013.

PELEIAS, I. R., NUNES, C. A., CARVALHO, R. F. Fatores determinantes na escolha do curso de Ciências Contábeis por estudantes de instituições de ensino superior particulares na cidade de São Paulo. Revista de Gestão Universitária na América Latina - GUAL, 10(3), 39-58, 2017.

PINHEIRO, R, G., SANTOS, M. R. Fatores de escolha pelo curso de Ciências Contábeis uma pesquisa com os graduandos na Capital e Grande São Paulo. In Resumos do XVIII Seminário de Administração, (p.01-16). São Paulo, SP, 2010.

POLITElO, L., MANFROI, L., CUNHA, P. R. O Mercado de Trabalho na Percepção dos Concluintes do Curso de Ciências Contábeis. Revista Catarinense da Ciência Contábil CRCSC, 12 (35), 79-98, 2013.

PRATAMA, A. Why do accounting students choose a career in accountancy? An exploratory study in Bandung City, West Java, Indonesia. Review of Integrative Business and Economics Research, 6(2), 393-407, 2017.

SANTOS, E. A., ALMEIDA, L. B. Seguir ou não carreira na área de contabilidade: um estudo sob o enfoque da Teoria do Comportamento Planejado. Revista Contabilidade e Finanças, 29 (76), 114-128, 2018. 
SOUZA, J.P., \& DURSO, S.O. A Motivação de Estudantes-Trabalhadores e TrabalhadoresEstudantes de Ciências Contábeis para a Realização da Graduação. In XV Congresso USP de Iniciação Científica em Contabilidade, 2018.

SRIREJEKI, K., SUPENO, S., FATURAHMAN, A. Understanding the Intentions of Accounting Students to Pursue Career as a Professional Accountant. Binus Business Review, 10(1), 01-10, 2019.

THING, O, G., JALALUDIN, D. Career Path in Accounting: What are the drivers? International Academic Journal of Accounting and Financial Management, 5(4), 66-82, 2018.

UMAR, I. Factors Influencing Students' Career Choice in Accounting: The Case of Yobe State University. Research Journal of Finance and Accounting, 5(17), 59-62, 2014.

UYAR, A., GÜNGÖRMÜŞ, A. H. KUZEY, C. Factors Affecting Students' Career Choice In Accounting: The Case Of A Turkish University. American Journal of Business Education, 4(10), 29-38, 2011.

WALLY-DIMA, L. B. Factors influencing students' choice of accounting as a major: the case of botswana accounting students. Asian Journal of Empirical Research, 3(4), 464-476, 2013. 